\title{
Prehypertension and Hypertension Risk Assessment Among Female Cotton Mill Workers
}

\author{
Divya Raichu Jacob and K. Nora Vigasini* \\ Department of Home Science, Women's Christian College, Affiliated to the University of Madras, \\ Chennai - 600 006, Tamil Nadu, India; divyaraichu@gmail.com, noravigasini267@gmail.com
}

\begin{abstract}
Aim of the Study: The present study aimed to determine the risk of prehypertension and hypertension and its association with certain occupational, sociodemographic and lifestyle determinants. Material and Methods: A descriptive study was conducted among 180 female cotton mill workers in the production sector of two cotton spinning mills in Central Travancore, Kerala. A questionnaire was framed to elicit information regarding occupational, sociodemographic and lifestyle variables. Blood pressure readings and anthropometric measurements like body height and weight were recorded. Results: The prevalence of prehypertension and hypertension among the workers were found to be $30 \%$ and $7.22 \%$ respectively. It was observed that age and body mass index were statistically significant with prehypertension and hypertension $(\mathrm{p}<0.05)$ compared to the number of years of employment in the mills, education, annual family income and physical activity which were not statistically significant. Pearson's correlation test revealed that age and body mass index were positively correlated with mean blood pressure. Conclusion: The present study observed a higher percentage of prehypertension among the workers. This stresses on the importance of early identification and control of more modifiable risk factors in the prevention and treatment of prehypertension and hypertension.
\end{abstract}

Keywords: Determinants, Lifestyle, Occupational, Statistically Significant

\section{Introduction}

A blue-collar worker is a skilled or unskilled person who performs manual labour ${ }^{1}$. A systematic review done between 1990 to 2015 found that there are emerging health problems especially among blue-collar women workers involved in the production and manufacturing sector. One of the observations was that the studies on the prevalence of health problems among blue-collar women are less when compared to that of blue-collar men². Therefore, more studies on the health problems of blue-collar women workers need to be conducted. In India, secondary industries like cotton mills which convert raw unprocessed cotton to processed cotton employ a large number of blue-collar women. The work-family balance of women may compound many ailments including the development of many non-communicable diseases including hypertension.

Recent publications on mean blood pressure and its associated factors among cotton mill workers are scarce. A study that was done to determine the prevalence of hypertension among 400 cotton mill workers estimated a rate of over $38 \%$ and $22.3 \%$ as prehypertensive and hypertensive.
The prevalence of hypertension in the study was on par with that of the general Indian population which is $21 \%$. However, the study included a heterogeneous group from all workers of the cotton mill industry from the production sector, office and maintenance; both males and females; with and without consumption of alcohol, smoking and tobacco ${ }^{3}$. Studies need to be conducted to determine the mean blood pressure and the prevalence of hypertension along with its associated factors exclusively among female cotton mill workers.

According to a study done among the multi-ethnic Asian population, it was found that age, gender, educational level, employment and family income are factors that affect

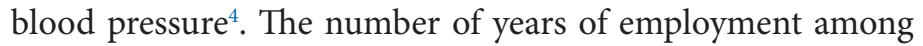
industrial workers is also another determinant that contributes to mean blood pressure due to the occupational irritants, noise and stress in the work environment ${ }^{5}$. The common lifestyle determinants of health are food choices, physical activity, healthy body weight, tobacco, smoking, alcohol consumption and drug use $\mathrm{e}^{6}$. These are also identified as the risk factors of hypertension among the workers of the cotton mill industry ${ }^{7}$. All of these sociodemographic, lifestyle and occupational

${ }^{*}$ Author for correspondence 
factors are important in determining the mean blood pressure among workers of the cotton mill industry.

The present study aimed to determine the risk of prehypertension and hypertension among female cotton mill workers in the production sector of the cotton mill industry. The objective was to determine the mean blood pressure and its relationship with sociodemographic, lifestyle and occupational determinants among the workers.

\section{Materials and Methods}

A descriptive study design was conducted in February 2020 among 180 female cotton mill workers in the production sector of two cotton spinning mills located in Central Travancore of the Kerala state in India. All female cotton mill workers aged between 20 to 60 years in the production sector of the cotton mill were included in the study based on the willingness to participate. All men were excluded from the study. The study protocol was approved by the Institutional Ethics Committee of the Department of Home Science, Women's Christian College, Chennai before the data collection and informed consent was obtained. The tools involved in the data collection are given below.

\subsection{Questionnaire}

A questionnaire was framed to assess the occupational, sociodemographic and lifestyle determinants of blood pressure. Occupational details included the number of years of employment in the cotton mill industry. Sociodemographic details like age, education level and family income were elicited from the questionnaire. Lifestyle characteristics like physical activity, consumption of alcohol, smoking and tobacco usage were included. This was followed by the assessment of anthropometric measurements like body height and body weight.

\subsection{Body Height and Weight}

Body height was measured using a stadiometer (measured in $\mathrm{m}^{2}$ ) and body weight (measured in $\mathrm{kg}$ ) was assessed using a portable weighing machine. Body mass index was calculated as weight (in $\mathrm{kg}$ ) divided by height (in $\mathrm{m}^{2}$ ). According to World Health Organization (2004) body mass index classification for Asians, the cut-off points for underweight, normal, overweight and obese individuals are less than $18.5 \mathrm{~kg} / \mathrm{m}^{2}, 18.5$ to $\geq$ $24.99 \mathrm{~kg} / \mathrm{m}^{2}, \geq 25$ to $29.99 \mathrm{~kg} / \mathrm{m}^{2}$ and $\geq 30 \mathrm{~kg} / \mathrm{m}^{2}$ respectively. Underweight individuals can be classified into severe thinness $\left(<16 \mathrm{~kg} / \mathrm{m}^{2}\right)$, moderate thinness (16 to $\left.16.99 \mathrm{~kg} / \mathrm{m}^{2}\right)$ and mild thinness $\left(17\right.$ to $18.49 \mathrm{~kg} / \mathrm{m}^{2}$ ). Individuals with body mass index between 25 to $29.99 \mathrm{~kg} / \mathrm{m}^{2}$ were classified as pre-obese. Body mass indexes between 30 to $34.99,35$ to 39.99 and $\geq 40 \mathrm{~kg} / \mathrm{m}^{2}$ were classified under obese class 1, 2 and 3 respectively ${ }^{8}$. The mean body height and weight were also calculated from all the study participants.

\subsection{Mean Blood Pressure}

Blood pressure was monitored using a digital wrist blood pressure monitor (OMRON HEM 608) which is a validated instrument for monitoring blood pressure ${ }^{9}$. The blood pressure was recorded on the right arm of each study participant and an average of three recordings was taken after the individual had rested for 5 minutes. The first two readings were taken 1 minute apart. A total of three recordings were taken and mean blood pressure was calculated ${ }^{10}$. Based on the mean blood pressure readings, the study participants were classified into normal, prehypertensive and hypertensive groups according to the JNC-7 criteria ( $7^{\text {th }}$ Joint National Committee on Prevention, Detection, Evaluation and Treatment of High Blood Pressure $)^{11}$. The classification based on JNC-7 criteria is represented in Table 1.

\subsection{Statistical Analysis}

Statistical tests like mean, standard deviation and chi-square test were calculated using excel 2010. Descriptive statistics that involved frequencies and percentages were also represented.

\section{Results}

\subsection{Number of Years of Employment in The Cotton Mills}

A recent study indicated that oxidative stress and inflammation are common among cotton mill workers which makes them more susceptible to developing non-communicable diseases including hypertension ${ }^{12}$. The number of years of employment in the cotton mill industry between 1 to 10 years, 11 to 20 years and 21 to 30 years were $58.88 \%, 40 \%$ and $1.11 \%$ respectively. Duration of exposure to cotton dust is equivalent to the number of years of employment in the industry. In the present

Table 1. Classification of blood pressure according to JNC-7 criteria

\begin{tabular}{|l|l|}
\hline $\begin{array}{l}\text { JNC-7 criteria for } \\
\text { blood pressure }\end{array}$ & $\begin{array}{l}\text { Systolic/Diastolic blood pressure } \\
\text { readings }(\mathbf{m m} \mathbf{H g})\end{array}$ \\
\hline Normal & $<120 / 80$ \\
\hline Prehypertension & $120-139 / 80-89$ \\
\hline Hypertension & $\begin{array}{l}\geq 140 / 90 \\
140-159 / 90-99(\text { Stage } 1) \\
160-179 / 100-109 \text { and } \geq 180 / 110 \\
(\text { Stage } 2)\end{array}$ \\
\hline
\end{tabular}


study, the majority of the individuals had work experience within 20 years.

\subsection{Body Mass Index}

The body mass index was assessed among 180 female cotton mill workers involved in the production sector of the cotton mill. It was found that 9 individuals (5\%) came under the obese category $\left(\geq 30 \mathrm{~kg} / \mathrm{m}^{2}\right)$, out of which 8 individuals had class 1 obesity $\left(30-34.99 \mathrm{~kg} / \mathrm{m}^{2}\right)$ and 1 individual had obesity class 3 $\left(\geq 40 \mathrm{~kg} / \mathrm{m}^{2}\right)$. Sixty-eight (37.77\%) individuals were overweight or pre-obese $\left(\geq 25.00-29.99 \mathrm{~kg} / \mathrm{m}^{2}\right)$. Ninety $(50 \%)$ individuals were having normal BMI (18.50-24.99 kg/m²). Twelve (6.66\%) individuals were underweight $\left(<18.50 \mathrm{~kg} / \mathrm{m}^{2}\right)$, out of which 4 individuals had mild thinness, 6 individuals had moderate thinness and 1 individual had severe thinness.

\subsection{Mean Blood Pressure of Cotton Mill Workers}

An average of the three blood pressure readings was recorded among the study participants to estimate the mean blood pressure using OMRON HEM 608. Out of the 180 female cotton mill workers, 113 individuals (62.77\%) had normal blood pressure, $54(30 \%)$ individuals were prehypertensive and 13 (7.22\%) individuals were hypertensive. Among the 13 hypertensive individuals, 8 individuals had stage 1 hypertension and 5 individuals had stage 2 hypertension. The mean systolic blood pressure was found to be $117.67 \pm 3.17 \mathrm{mmHg}$ and the mean diastolic blood pressure was found to be $75.84 \pm 2.71 \mathrm{~mm} \mathrm{Hg}$.

\subsection{Age}

In the present study, the mean age of the study participants was $39.16 \pm 6.19$ years. Several studies indicate a positive correlation between age and hypertension. Some of the reasons behind hypertension are oxidative stress, inflammation and endothelial dysfunction associated with aging ${ }^{13}$. In a study done among 16,000 adults in three cities of South Asia, $26.8 \%$ of hypertension was found among $52 \%$ of women whose mean age was 40 years $^{14}$.

\subsection{Educational Qualification and Annual Family Income}

In the present study, $49.99 \%$ had completed primary school, $42.22 \%$ had completed high school, $7.22 \%$ had completed secondary school and $0.55 \%$ had completed undergraduate program. There was no individual without any formal schooling. According to the policy scheme 'Pradhan Mantri Awas Yojana' in 2015 (Ministry of Housing and Urban Poverty Alleviation, Government of India) $)^{15}$, all the study participants came under the economically weaker section. A recent study observed that there was little or no correlation between individuals with higher educational qualifications and hypertension ${ }^{16}$. The same study also observed that a higher socioeconomic position is positively correlated with hypertension. This means that educational qualification and annual family income are not significant determinants of mean blood pressure in the present study.

\subsection{Lifestyle Habits Like Smoking, Alcohol Consumption and Tobacco Usage}

None of the individuals had lifestyle habits like smoking, alcohol consumption and tobacco usage which are significant risk factors for hypertension ${ }^{17}$.

\subsection{Physical Activity}

The cotton mill industry is one of the largest labour-intensive sectors in Kerala with workers involved in the conversion of unprocessed cotton to processed yarn by operating sophisticated machines. Such blue-collar workers are physically active at their workplaces than during their leisure time ${ }^{18}$. In the present study, only a lesser portion of the individuals (15.55\%) did physical activity regularly. A major proportion of the individuals (84.44\%) did not do any physical activity due to lack of time.

\subsection{Statistical Analysis}

The relationship between sociodemographic, lifestyle and occupational determinants of prehypertension and hypertension using chi-square test is represented in table 2 and 3. The association of age and body mass index with prehypertension and hypertension was found to be statistically significant. Positive correlation of age with systolic and diastolic blood pressures were observed $(r=0.368$ and $r=0.276$, significant at $\mathrm{p}<0.01)$. Positive correlation of body mass index with systolic and diastolic blood pressures were observed $(\mathrm{r}=0.272$ and $\mathrm{r}=0.289$, significant at $\mathrm{p}$ value $<0.01)$. 
Table 2. Sociodemographic determinants of prehypertension and hypertension

\begin{tabular}{|c|c|c|c|c|c|}
\hline Risk factors & Particulars & Prehypertension & Hypertension & Chi-Square & $p$ value \\
\hline \multirow[t]{4}{*}{ Age (in years) } & $20-30$ & 4 & 0 & \multirow[t]{4}{*}{26.16} & \multirow[t]{4}{*}{$0.0019^{\star *}$} \\
\hline & $31-40$ & 21 & 3 & & \\
\hline & $41-50$ & 25 & 10 & & \\
\hline & $51-60$ & 4 & 0 & & \\
\hline \multirow{4}{*}{$\begin{array}{l}\text { Body Mass Index } \\
\left(\mathrm{kg} / \mathrm{m}^{2}\right)\end{array}$} & $<18.5$ & 0 & 0 & \multirow[t]{4}{*}{21.09} & \multirow[t]{4}{*}{$0.012^{\star *}$} \\
\hline & $18.5-24.9$ & 2 & 1 & & \\
\hline & $25-29.9$ & 13 & 5 & & \\
\hline & $\geq 30$ & 39 & 7 & & \\
\hline \multirow{3}{*}{$\begin{array}{l}\text { Educational } \\
\text { qualification }\end{array}$} & Primary school & 28 & 9 & \multirow[t]{3}{*}{2.55} & \multirow[t]{3}{*}{$0.63^{\mathrm{NS}}$} \\
\hline & High school & 21 & 3 & & \\
\hline & $\begin{array}{l}\text { Higher secondary } \\
\text { school/college }\end{array}$ & 5 & 1 & & \\
\hline \multirow[t]{4}{*}{ Family income } & $\begin{array}{c}\text { Rs 20,000-Rs Rs } \\
40,000\end{array}$ & 30 & 9 & \multirow[t]{4}{*}{4.13} & \multirow[t]{4}{*}{$0.65^{\mathrm{NS}}$} \\
\hline & Rs 41,000 -Rs 60,000 & 12 & 3 & & \\
\hline & Rs 61,000 -Rs 80,000 & 5 & 1 & & \\
\hline & $\begin{array}{c}\text { Greater than Rs } \\
80,000\end{array}$ & 7 & 0 & & \\
\hline
\end{tabular}

${ }^{* *}$ represents statistically significant at $\mathrm{p}<0.05$

${ }^{\mathrm{NS}}$ represents not significant

Table 3. Lifestyle and occupational determinants of prehypertension and hypertension

\begin{tabular}{|c|c|c|c|c|c|}
\hline Risk factors & Particulars & Prehypertension & Hypertension & Chi-Square & p value \\
\hline \multirow[t]{2}{*}{ Physical activity } & Yes & 9 & 1 & \multirow[t]{2}{*}{0.674} & \multirow[t]{2}{*}{$0.879^{\mathrm{NS}}$} \\
\hline & No & 45 & 12 & & \\
\hline \multirow{3}{*}{$\begin{array}{l}\text { Years of employment } \\
\text { in the cotton mill } \\
\text { industry }\end{array}$} & $1-10$ & 27 & 9 & \multirow[t]{3}{*}{4.343} & \multirow[t]{3}{*}{$0.630^{\mathrm{NS}}$} \\
\hline & $11-20$ & 27 & 4 & & \\
\hline & $21-30$ & 0 & 0 & & \\
\hline
\end{tabular}

${ }^{N S}$ represents not significant

\section{Discussion}

The overall prevalence of hypertension among South Asians is 30.7 per cent according to the 2011 census population in India ${ }^{19}$. A previous study reported $38 \%$ prehypertensive and $22.3 \%$ hypertensive individuals in the cotton mill industry in Kannur of Kerala state ${ }^{20}$. This was a largely heterogeneous group involving both genders, irrespective of lifestyle characteristics. The present study which involved only females, reported only $7.22 \%$ hypertensive individuals. Even though the per cent of hypertension was less, a higher proportion of 30 per cent were prehypertensive. The individuals with prehypertensive systolic and diastolic blood pressures (130-139/80-89 $\mathrm{mm} \mathrm{Hg}$ ) are at twice the risk of developing hypertension that those with lower values of blood pressure ${ }^{21}$.
The prehypertension rate in the present study was found to be significantly higher than that of hypertension. Among sociodemographic, lifestyle and occupational determinants, the main determinants of prehypertension and hypertension in the present study were found to be age and body mass index which was statistically significant with mean blood pressure at $\mathrm{p}<0.05$. Other determinants like educational qualification, annual family income, physical activity and years of employment in the cotton mill industry were not statistically significant (represented in table 2 and 3 ).

The mean age in the present study was similar to that of a recent large-scale survey which reported that $52 \%$ of women have a mean age of 40 years $^{14}$. In a study done among 179 female textile workers in Puducherry between 21 to 40 years, it was found that $39.1 \%$ were pre-obese and $12.8 \%$ were obese ${ }^{22}$. The 
present study estimated a lower per cent of obese individuals (6.66\%). However, a greater per cent (38.8\%) was observed to be in the overweight criteria.

The present study indicated that the sociodemographic factors like educational qualification and annual family income were not statistically significant determinants of prehypertension and hypertension. Regular physical activity was done only by $15.55 \%$ of the individuals. Physical activity was also statistically insignificant with prehypertension and hypertension. In the present study, majority of the individuals (98.88\%) had work experience within 20 years. The number of years of experience in the cotton mill also did not show statistical significance.

The limitation of the present study was that it did not involve more occupational determinants (like occupational stress, noise) and dietary factors that could be associated with hypertension. A recent systemic review to determine the prevalence of hypertension and its risk factors among cotton mill workers in low and middle-income countries indicated that excessive salt intake, too little potassium in the diet, stress and other chronic conditions like kidney disease, diabetes and sleep apnea are also potential risk factors for hypertension? The mean blood pressure of individuals in prehypertensive groups can be modified by controlling the mean blood pressure through proper dietary practices. Identification of potential dietary risk factors among cotton mill workers and controlling them through proper dietary practices can be the direction for future research.

\section{Conclusion}

The present study observed a higher percentage of prehypertensive individuals who have a greater risk of becoming hypertensive in the future. Age and body mass index was observed to be significant factors associated with prehypertension and hypertension. It is important to identify more risk factors to control and prevent the risk of developing hypertension.

\section{Acknowledgements}

The authors would like to thank the workers of cotton mills in Central Travancore for their voluntary participation in the study.

\section{References}

1. Lips-Wiersma M. Wright S. Dik BJ. Meaningful work: differences among blue-, pink, and white-collar occupations. Career Development International. Aug 2016; 21 (5): 534-551. https:// www.researchgate.net/publication/308042364_Meaningful_ work_differences_among_blue-_pink-_and_white-collar_occupations; https://doi.org/10.1108/CDI-04-2016-0052

2. Elser H. Falconi AM. Bass M. Cullen MR. Blue-collar work and women's health: a systematic review of the evidence from 1990 to 2015. SSM Popul Health. Aug 2018; 6:195-244. https:// pubmed.ncbi.nlm.nih.gov/30417066/; https://doi.org/10.1016/j. ssmph.2018.08.002

3. Ismail IM. Binub K. Prevalence of hypertension and its associated factors among cotton textile workers of Kannur, Kerala. Menoufia Medical Journal. Mar 2016; 29(4): 991. https://www. mmj.eg.net $/$ article.asp? issn $=11102098$; year $=2016$; volume $=29$;iss ue $=4$; page $=991$; epage $=995$; aulast $=$ Ismail

4. Liew SJ. Lee JT. Tan, CS. Koh CHG. Van Dam R. MüllerRiemenschneider F. Sociodemographic factors in relation to hypertension prevalence, awareness, treatment and control in a multi-ethnic Asian population: a cross-sectional study. BMJ Open. Apr 2016; 9(5). https://bmjopen.bmj.com/content/9/5/ e025869; https://doi.org/10.1136/bmjopen-2018-025869

5. Bosu WK. Determinants of mean blood pressure and hypertension among workers in West Africa. Int J Hypertens. Jan 2016; 1-19. https://www.hindawi.com/journals/ijhy/2016/3192149/; https://doi.org/10.1155/2016/3192149

6. Farhud DD. Impact of lifestyle on health. Iran J Public Health. Oct 2015;44(11):1442-1444. https://www.ncbi.nlm.nih.gov/ pmc/articles/PMC4703222/

7. Akber Ali N. Shahil Feroz A. Prevalence of hypertension and its risk factors among cotton textile workers in low- and middleincome countries: a protocol for a systematic review. Syst Rev. May 2020; 9(1). https://pubmed.ncbi.nlm.nih.gov/32359375/; https://doi.org/10.1186/s13643-020-01364-z

8. WHO expert consultation. Appropriate body-mass index for Asian populations and its implications for policy and intervention strategies. The Lancet, Mar 2004; 157-163. https://pubmed. ncbi.nlm.nih.gov/14726171/; https://doi.org/10.1016/S01406736(03)15268-3

9. Plavnik FL. Zanella MT. Validation study of an automated wrist monitor, omron model HEM-608, compared with the standard methods for blood pressure measurement. Arq Bras Cardiol. Dec 2001; 77(6): 537-540. https://pubmed. ncbi.nlm.nih.gov/11799428/; $\quad$ https://doi.org/10.1590/S0066782X2001001200004

10. Muntner P. Shimbo D. Carey RM. Charleston JB. Gaillard T. Misra S. Measurement of blood pressure in humans: a scientific statement from the American heart association. Hypertension. Mar 2019; 73: e35-e66. https://pubmed.ncbi.nlm.nih.gov/30827125/; https://doi.org/10.1161/HYP.0000000000000087

11. Chobanian AV. Bakris GL. Black HR. Cushman WC. Green LA. Izzo JL et al. The seventh report of the joint national committee on prevention, detection, evaluation, and treatment of high blood pressure: the JNC 7 report. JAMA. May 2003; 289(19): 2560-72. https://pubmed.ncbi.nlm.nih.gov/12748199/; https:// doi.org/10.1001/jama.289.19.2560

12. Dangi B. Bhise A. Cotton dust exposure: analysis of pulmonary function and respiratory symptoms. Lung India. Jul 2017; 34(2): 
144-9. https://pubmed.ncbi.nlm.nih.gov/28360462/; https://doi. org/10.4103/0970-2113.201319

13. Buford TW. Hypertension and aging. Ageing Res Rev. Mar 2016; 26: 96-111. https://www.ncbi.nlm.nih.gov/pmc/articles/ PMC4768730/; https://doi.org/10.1016/j.arr.2016.01.007

14. Prabhakaran D. Jeemon P. Ghosh S. Shivashankar R. Ajay VS. Kondal D et al. Prevalence and incidence of hypertension: results from a representative cohort of over 16,000 adults in three cities of South Asia. Indian Heart J. Aug 2017; 69(4): 434-441. https:// pubmed.ncbi.nlm.nih.gov/28822507/; https://doi.org/10.1016/j. ihj.2017.05.021

15. Ministry of housing and urban poverty alleviation. Government of India: Pradhan Mantri Awas Yojana Scheme Guidelines, Jun 2015. http://mohua.gov.in/upload/uploadfiles/files/2TPQMA_ Guidelines_for_Print\%242017Jun28155048.pdf

16. Thrift AG. Ragavan RS. Riddell MA. Joshi R. Thankappan KR. Chow C. Hypertension in rural India: the contribution of socioeconomic position. Journal of the American Heart Association. Apr 2020; 9(7). https://www.ahajournals.org/doi/full/10.1161/ JAHA.119.014486; https://doi.org/10.1161/JAHA.119.014486

17. Unger T. Borghi C. Charchar F. Khan NA. Poulter NR. Prabhakaran $\mathrm{D}$ et al. International society of hypertension global hypertension practice guidelines. Hypertension. Jun 2020; 75(6): 1334-1357. https://pubmed.ncbi.nlm.nih.gov/32370572/; https://doi.org/10.1161/HYPERTENSIONAHA.120.15026

18. Azevedo LM. Chiavegato LD. Carvalho CRF. Braz JR. Nunes Cabral CM. Padula RS. Are blue-collar workers more physically active than white-collar at work? Arch Environ Occup Health. Oct 2020; 23:1-10. https://pubmed.ncbi.nlm.nih.gov/33092496/; https://doi.org/10.1080/19338244.2020.1835796

19. Ramakrishnan S. Zachariah G. Gupta K. Shivkumar Rao J. Mohanan PP. Venugopal K et al. Prevalence of hypertension among Indian adults: results from the great India blood pressure survey. Indian Heart Journal. Aug 2019; 71(4): 309-313. https:// pubmed.ncbi.nlm.nih.gov/31779858/

20. Popescu SM. Scrieciu M. Mercuţ V. Ţuculina, M. Dascălu I. Hypertensive patients and their management in dentistry. ISRN Hypertension. Oct 2013; 1-8. https://www.hindawi.com/journals/isrn/2013/410740/; https://doi.org/10.5402/2013/410740

21. Punitha KP. Subitha L. Gautam R. Pattern of morbidity among female textile workers in Puducherry, South India. Int J Med Public Health. Aug 2016; 6(3):140-143. https://www.ijmedph. org/article/472; https://doi.org/10.5530/ijmedph.2016.3.9 